\title{
ON THE SEGREGATION OF CARBON IN A PIECE OF BOILER PLATE.
}

BY HENRY FAY AND HENRY P. TALBOT

Receivect june $x_{5}, 18 ; 8$.

\begin{abstract}
$A$ PIECE of steel has recently come into our hands for exam$A$ ination which, by its unusual and striking properties, strongly emphasizes the necessity for careful heat treatment. The specimen was a circular steel plate, one-fourth inch in thickness and about three feet in diameter, and was intended for use as the head-piece of a pressure cylinder to hold carbon dioxide.

Unfortunately, the complete history of the piece was not obtainable, but it is known that after its receipt from the manufacturers the plate was twice annealed and was then to be punched into a cup-shaped cylinder head. On flanging, however, the plate cracked around the entire bend, which was made about four inches from the circumference, the cracks being fully one-sixteenth inch deep and more than an inch long.

Samples for analysis were taken from the edge of the plate and from the center, and test pieces were also taken from both portions for examination as to tensile strength and elongation. The specifications called for a mild steel containing about 0.30 per cent. carbon.
\end{abstract}

The results of the analysis are tabulated below:

\begin{tabular}{|c|c|c|}
\hline & $\begin{array}{l}\text { ter portionl. } \\
\text { Per cent. }\end{array}$ & $\begin{array}{l}\text { Center portion. } \\
\text { Per cent. }\end{array}$ \\
\hline \multirow{5}{*}{ Phosphorus........... } & 0.005 & 0.006 \\
\hline & 0.004 & 0.008 \\
\hline & 0.003 & 0.005 \\
\hline & 0.006 & 0.005 \\
\hline & $\ldots$ & 0.004 \\
\hline \multirow{3}{*}{ Sulphur $\ldots \ldots \ldots \ldots \ldots$} & 0.033 & 0.050 \\
\hline & 0.042 & 0.050 \\
\hline & 0.033 & 0.040 \\
\hline \multirow[t]{2}{*}{ Manganese...$\ldots \ldots \ldots$} & 0.36 & $0.3^{8}$ \\
\hline & 0.37 & 0.38 \\
\hline \multirow[t]{9}{*}{ Carbon...$\ldots \ldots \ldots \ldots$} & 0.130 & 0.087 \\
\hline & 0.036 & 0.070 \\
\hline & O.IIO & 0.124 \\
\hline & 0.156 & 0.060 \\
\hline & 0.067 & 0.090 \\
\hline & 0.080 & 0.030 \\
\hline & 0.076 & $0.09 \mathrm{I}$ \\
\hline & $\ldots$ & 0.070 \\
\hline & $\ldots$ & 0.100 \\
\hline
\end{tabular}


It will be noted that, with the exception of the carbon and sulphur, the percentages represent about normal values for a steel which would be suitable for the purpose named.

The carbon determinations, on the other hand, exhibit the most astonishing variations, ranging between 0.036 and 0.156 per cent. in the outer portions, and 0.060 and 0.124 per cent. in the center. A thorough examination of chemicals and apparatus, and repeated blank analyses, made it certain that errors from these sources were eliminated, and it only remained to conclude that the varying percentages represented inequalities in the composition of the material under analysis.

For the physical tests, made by Professor E. F. Miller, of the Massachusetts Institute of Technology, three test pieces were taken, one of which was from the flange where the crack showed, the others from the unbent portion. The specimen from the flange was straightened by being heated to a bright cherry-red, and the tensile strength was determined in the usual way. The fracture did not take place at the point where the crack occurred, as one might expect.

The following results were obtained:

$\begin{array}{lccc} & \text { I. } & 2 . & \begin{array}{c}3 . \\ \text { Test-piece } \\ \text { from flange. }\end{array} \\ \text { Dimensions of cross-section... } & \mathbf{2}^{\prime \prime} \times 0.3850^{\prime \prime} & 2{ }^{\prime \prime} \times 0.3850^{\prime \prime} & \mathbf{2} " \times 0.380^{\prime \prime} \\ \text { Tensile strength............ } & 44,690 & 44,670 & 45,960 \\ \text { Elongation............... } & 28.1 & \ldots . & \ldots \ldots\end{array}$

It will be seen that the material would probably have been rejected on account of low tensile strength, not to mention the fact that the carbon determinations had shown the material to be far from homogeneous.

The results of the physical tests, however, threw no light upon the cause of the inequalities in the carbon contents of the steel, but upon etching a small, roughly polished portion with dilute nitric acid (sp. gr. I.I3), the fact was at once demonstrated that the steel was badly crystallized.

Other portions of the plate were then cut and carefully polished with various grades of emery and finally with rouge. This polishing served to etch the samples sufficiently to permit of an examination with the microscope which, in turn, showed the carbon to be unevenly distributed throughout the mass. 
Upon etching the surface a trifle more deeply, in relief, with dilute nitric acid (sp. gr. I.I3), the grains of ferrite were very clearly brought out, as can be seen in the accompanying cut (Fig. I), which represents the crystals in their natural size.

A similar examination of the edge of the plate made it evident that the crystallization had penetrated only part way through the mass. A glance at Fig. 2 will show the depth to which the crystallization had extended.

The test pieces which were subjected to the tensile tests also show this superficial crystalline structure in a peculiar way. Instead of pulling uniformly and breaking sharply, the crystalline layers slipped along on the non-crystalline portion and the surface was more or less pitted as a result of the depression of some of the crystals and the elevation of others, caused by the breaking apart of the separate crystals. The uniformity with which the crystalline structure has penetrated the metal, and this slipping of the two layers would seem to suggest that the plate was the "composition metal" of trade, or had been made by the process of "piling." Without a knowledge of the early history of the plate it is impossible to speak conclusively upon this point.

Sauveur" has shown experimentally that $(a)$ "a slow and undisturbed cooling from a temperature $x$ or higher, produces crystallization; (b) undisturbed cooling from an initial temperature lower than $x$ is not accompanied by crystallization; (c) the higher the initial temperature from which the steel is allowed to cool undisturbed, the larger the grain for a given composition." Again, Osmond, ${ }^{2}$ in discussing the heat treatment of steels, states that "in proportion as the temperature of annealing is elevated, the polyhedra of ferrite increases in size."

In the specimen under examination the grains of ferrite are not only visible to the unaided eye but some of them are of unusual size, measuring in transverse section as much as $1.5 \times$ $1 \mathrm{~cm}$., and there is further evidence of the faulty heat treatment in the microstructure which shows an uneven distribution of the pearlyte. There is therefore very little doubt that this specimen of steel has been subjected, during the annealing process, to a

1 Trans. Am. Inst. Min. Eng., 22, 546.

2 Ibid., 22, 255 


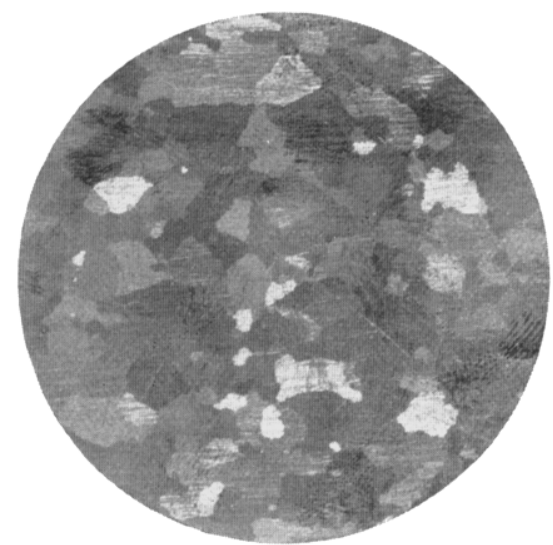

Fig. I. Showing grains of Ferrite. Natural size.

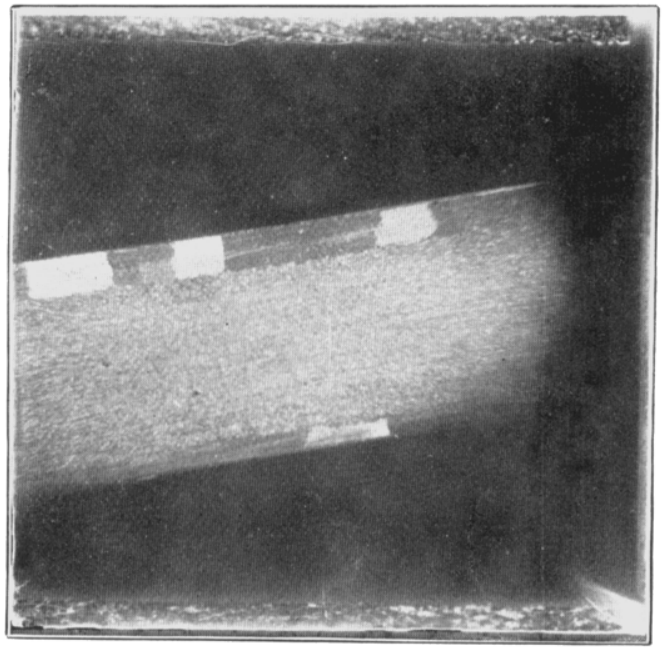

Fig. 2. Side view. Showing depth of crystallization.

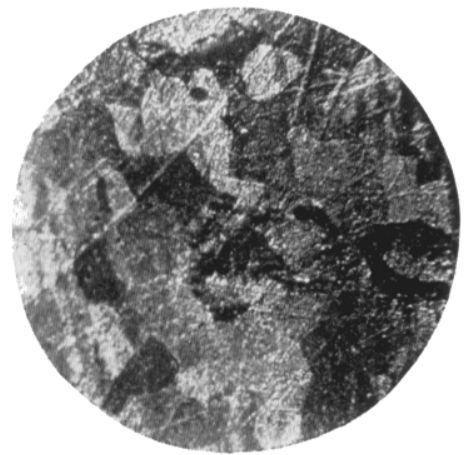

Fig. 3. Magnified about 30 diameters. 

temperature materially higher than that required, and has been allowed to cool extremely slowly. It is more than probable that the crystallization took place during the annealing process rather than during the manufacture of the plate, for the reason that cooling of the plate after rolling would necessarily be more rapid than after annealing, and to produce crystals of such size would require slow and undisturbed cooling.

The fact that the steel was overheated was further attested by the unusual thickness of the scale.

With respect to the variations in the percentage of carbon, it is safe to assume that the high temperature burned out a portion of the carbon and what remained had segregated during the process of crystallization, particles of carbon being distinctly visible on the polished surface with the help of a hand magnifying glass. That such a segregation of carbon may take place during crystallization is well demonstrated in a piece of openhearth steel (kindly sent to us by Mr. Kreuzpointer of the Pennsylvania Railroad Laboratory of Tests), which had broken through the bottom of the furnace and over which more than three hundred heats had been made. That the polished and etched surface shows a marked similarity to that of the steel for the pressure cylinder is evident from Fig. 3, which shows wellmarked crystals of ferrite, and the portion standing in relief is the segregated carbon, which can be seen in the sample with the unaided eye.

As has already been stated, the sharp line of demarcation between the crystalline exterior and non-crystalline interior, as shown in Fig. 2, suggests a "composition metal" and there is no definite evidence to disprove this. It may not, however, be out of place to ask the question: whether, if the heating of the plate in the furnace, although too strong, had yet been sufficient to effect it but partially, and if it had been at once transferred to the annealing oven where it could cool slowly, a similar result with respect to crystallization might not be within the bounds of possibility. Whether then the finished piece was originally composition metal or had been produced by the heating alone, there can be no doubt that it was ruined by the heat treatment. 